OPEN ACCESS

Edited by:

Jianhua Zhang,

Tianjin University, China

Reviewed by:

Fan Zhang,

Fudan University, China

Hong-Min Meng,

Zhengzhou University, China

*Correspondence:

Luis J. Cruz

I.j.cruz_ricondo@/umc.n!

Specialty section:

This article was submitted to

Nanoscience,

a section of the journal

Frontiers in Chemistry

Received: 24 March 2020

Accepted: 14 May 2020

Published: 17 June 2020

Citation:

Yu Z, Eich C and Cruz LJ (2020)

Recent Advances in

Rare-Earth-Doped Nanoparticles for

NIR-II Imaging and Cancer

Theranostics. Front. Chem. 8:496.

doi: $10.3389 /$ fchem.2020.00496

\section{Recent Advances in}

\section{Rare-Earth-Doped Nanoparticles for NIR-II Imaging and Cancer Theranostics}

\author{
Zhenfeng Yu, Christina Eich and Luis J. Cruz* \\ Translational Nanobiomaterials and Imaging Group, Department of Radiology, Leiden University Medical Center, Leiden, \\ Netherlands
}

Fluorescence imaging in the second near infrared window (NIR-II, 1,000-1,700 nm) has been widely used in cancer diagnosis and treatment due to its high spatial resolution and deep tissue penetration depths. In this work, recent advances in rare-earth-doped nanoparticles (RENPS) - a novel kind of NIR-II nanoprobes - are presented. The main focus of this study is on the modification of RENPs and their applications in NIR-II in vitro and in vivo imaging and cancer theranostics. Finally, the perspectives and challenges of NIR-II RENPs are discussed.

Keywords: NIR-II, rare-earth-doped nanoparticles, modification, in vitro and in vivo imaging, cancer theranostics

\section{INTRODUCTION}

Cancer is one of the world's most lethal diseases, and there are no particularly effective treatments to date. Cancer patients must endure chemotherapy and radiotherapy, followed by long-term medications, which are a great burden on their body and mind. For people not to be afflicted by cancer, it is necessary to diagnose the disease in an early stage and personalize treatments based on each patient's individual variability and medical profile (Rubin et al., 2014). Molecular imaging modalities can be useful for the comprehensive evaluation of essential biomolecules and can facilitate the non-invasive visualization of cell function and biochemical processes in biological systems (Kuimova et al., 2009; Weissleder et al., 2016; Yang et al., 2017a). They are well-recognized as powerful techniques that provide more comprehensive anatomical, physiological and functional information in early cancer detection, drug delivery, as well as monitoring treatment effectiveness (Quon and Gambhir, 2005; Weissleder and Pittet, 2008; Willmann et al., 2008). Currently, varieties of molecular imaging techniques are widely used in the medical field, including magnetic resonance imaging (MRI), X-ray computed tomography (CT), positron emission tomography (PET), single-photon emission tomography (SPECT), and optical fluorescent light imaging (FLI) (Figure 1). However, these methods have some disadvantages. For example, CT and MRI often require high doses of contrast agents; $\mathrm{PET}$ and SPECT require radioactive tracers that can put both patients and operators in danger (O'Leary et al., 1999; Mariani et al., 2001, 2002; Tsien, 2003). Also, they need to be optimized to obtain more accurate information due to their long scanning time and low sensitivity/spatial resolution (Toussaint et al., 1996; Paulus et al., 2000).

In recent years, optical imaging has attracted much attention in various fields, predominantly preclinical research because it provides excellent real-time visualization, high sensitivity and spatial resolution, especially in early detection and diagnosis of cancer. Generally, most of the conventional imaging agents operate in the short-wavelength region (e.g., the ultraviolet (UV) and visible 


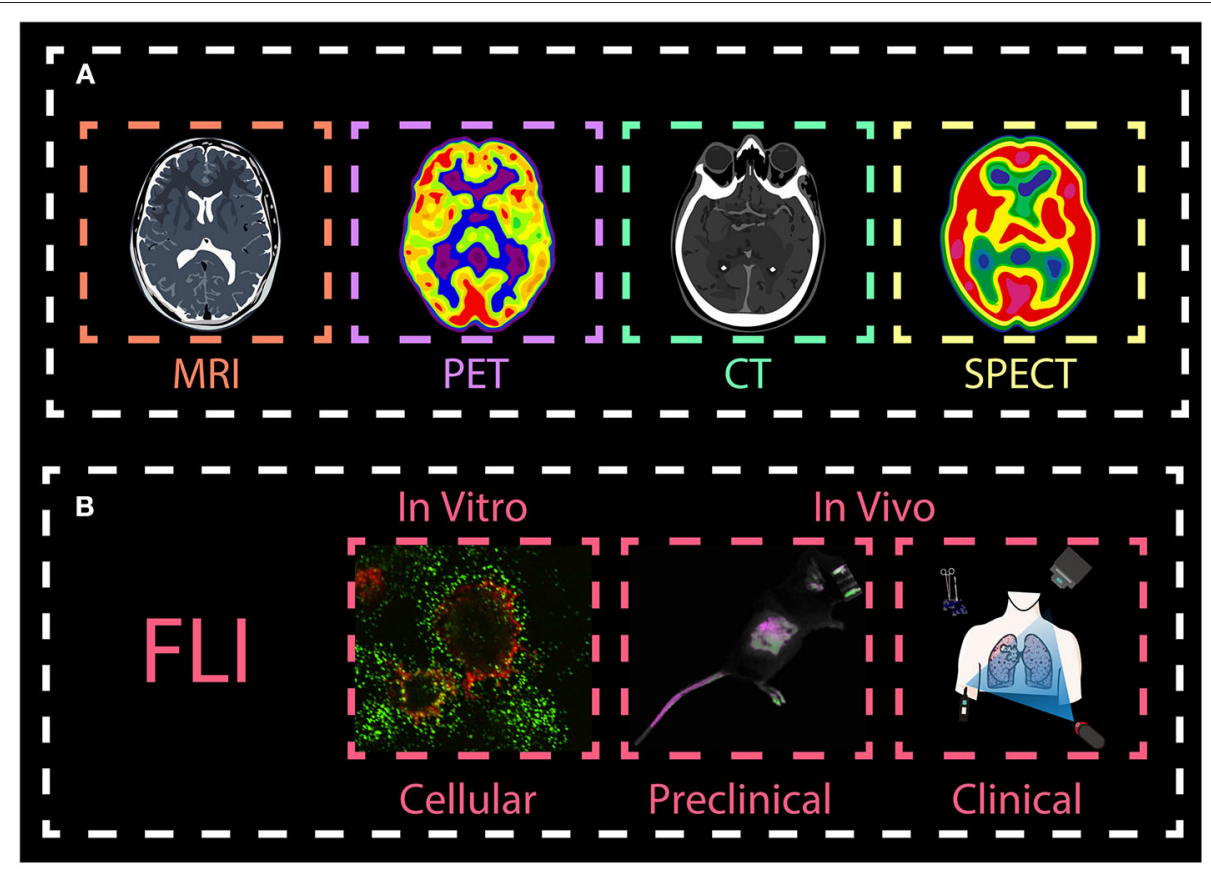

FIGURE 1 | Overview molecular imaging techniques. The main imaging methods are (A) magnetic resonance imaging (MRI), X-ray computed tomography (CT), positron emission tomography (PET), single-photon emission tomography (SPECT), and (B) optical fluorescent light imaging (FLI). While MRI, PET, CT, and SPECT are widely used in the clinics, FLI techniques are mainly used in biomedical preclinical research in vitro and in vivo, with the exception of fluorescence image-guided surgery, a medical imaging technique used to detect fluorescently labeled structures during surgery. This review, we will focus on introducing FLI from both in vitro and in vivo imaging.

regions). In these regions, light signals are easily absorbed and scattered by certain biological tissues (such as muscle, skin and body fluids). This leads to high autofluorescence, low signal-to-background ratio and low tissue penetration (Yang et al., 2017b,c). Besides, high-energy light can lead to photo-toxicity damage in biological tissues. To circumvent these problems, optical imaging in the near-infrared (NIR) region, which is located in the so-called "biological window," has gained much attention (Figure 2). Imaging agents in the first near-infrared window (NIR-I, 700-900 nm) are gradually being known by researchers, and can provide deep and sensitive bioimaging. However, their limited tissue penetration depth (less to $1 \mathrm{~cm}$ ) and large photon scattering losses in biological samples still restrict their use further in biomedical diagnosis and therapy. To address these challenges, novel materials that enable fluorescent imaging in the NIR-II window $(10,00-1,700 \mathrm{~nm})$ for biomedical applications have been developed. They show better resolution because they have deeper penetration $(\sim 1.8 \mathrm{~cm})$ and lower autofluorescence. Therefore, there is need to synthesize the novel NIR-II agents with high efficiency and resolution for biological imaging application (Fan and Zhang, 2019).

So far, many types of fluorescent agents with emission in the NIR-II region have been extensively applied for effective bio-sensing and real-time in vitro and in vivo imaging of living species (Figure 2). They include single-walled carbon nanotubes (SWNTs) (Gong et al., 2013; Liang et al., 2014), organic dyes (Lei et al., 2019; Wang et al., 2019a), conjugated polymers (Hong et al., 2014), quantum dots (QDs) (Li C. et al., 2014), and rare-earth-doped nanoparticles (RENPs) (Fan et al., 2019; Wang et al., 2019b). However, most of them have some disadvantages, such as the broad emission bandwidths of SWNTs, short accumulation time of organic dyes, high toxicity, low quantum yield and low solubility of QDs. These disadvantages will vastly inhibit their further applications in NIR-II imaging. RENPs are good candidates for NIR-II optical imaging, because they show minimal photo-bleaching, superior luminescent lifetimes, excellent tunable emission wavelengths and low biotoxicity (Rocha et al., 2014; Wang et al., 2014; Dong et al., 2015; Hemmer et al., 2016; Jiang et al., 2016; Kamimura et al., 2017).

Rare earth elements constitute a class of lanthanide ions found in the 6th row of the periodic table ( $\mathrm{La}, \mathrm{Ce}, \mathrm{Pr}, \mathrm{Nd}$, Pm, Sm, Eu, Gd, Tb, Dy, Ho, Er, Tm, Yb, Lu), as well as two other elements closely related to the lanthanides-yttrium (Y) and scandium $(\mathrm{Sc})$. Due to the incompletely filled $4 \mathrm{f}$ shell and the spin-orbital coupling of $4 \mathrm{f}$ free ions, they possess extremely complex optical properties. One of the most interesting features of these ions is their photoluminescence. The luminescence of the trivalent lanthanide ions arises from $\mathrm{f}-\mathrm{f}$ transitions of the $4 \mathrm{f}$ shell and $\mathrm{f}-\mathrm{d}$ transitions in the $4 \mathrm{f}-5 \mathrm{~d}$ shell. The $\mathrm{f}-\mathrm{f}$ transitions also provide the lanthanide elements with rich energy level structures in the UV, VIS and NIR ranges. As they can be tuned from the UV to the NIR region, most nanomaterials made of rare-earth elements can be classified into two major categories: Upconversion nanoparticles (UCNPs) and downconversion 


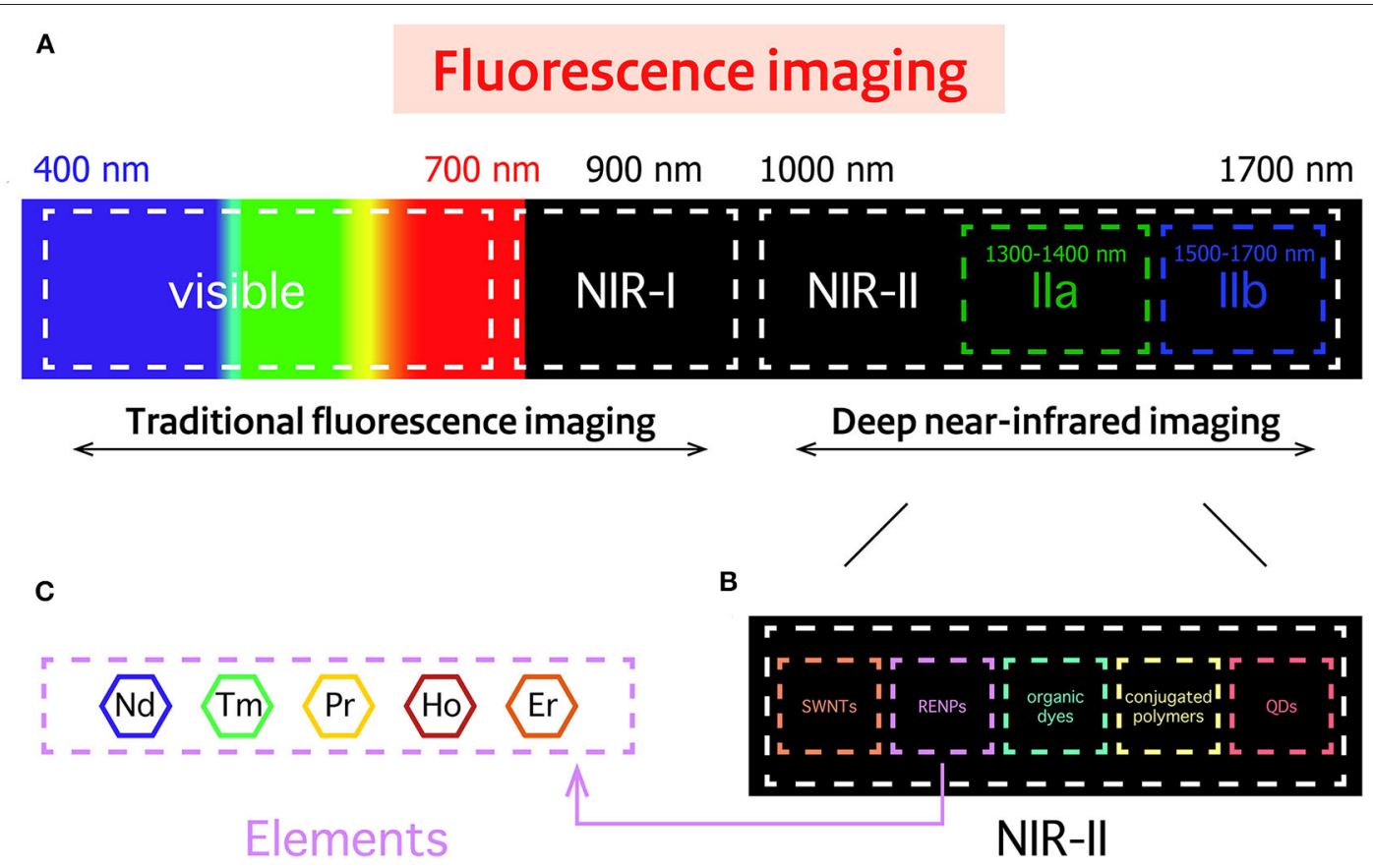

FIGURE 2 | Spectral overview fluorescence imaging techniques. (A) Spectral ranges of traditional fluorescence imaging techniques, including the near-infrared (NIR)-I region, and the deep NIR-II region. (B) Imaging probes commonly used in the NIR-II region: Single walled nanotubes (SWNTS), rare-earth-doped nanoparticles (RENPs), organic dyes, conjugated polymers, and quantum dots (QDs). (C) Neodymium (Nd)-, thulium (Tm)-, praseodymium (Pr)-, holmium (Ho)-, and erbium (Er)-containing RENPs have attracted wide attention.

nanoparticles (DCNPs). DCNPs can downconvert a high energy photon into two or more low-energy photons. In contrast, UCNPs can convert long-wavelength light (low energy) to short wavelength (high energy). Unfortunately, due to the unique anti-Stokes optical properties of UCNPs, most of the NIR-II nanoprobes belong to the category of DCNPs. Until now, a large number of studies have shown that by using suitable sensitizers, UCNPs can obtain longer excitation wavelength for NIR-II imaging (Zhang et al., 2020). For example, emissions in the NIR-II region of $\mathrm{Ho}^{3+}$ and $\mathrm{Nd}^{3+}$ could be obtained from $\mathrm{Er}^{3+}$ sensitized UCNPs (Liu et al., 2018).

Based on the excellent characteristics of rare-earth ions, such as their low photobleaching, various absorption and emission wavelengths, and low energy losses, NIR lightmediated RENPs have been widely used in in vitro and in vivo imaging of biomolecules. Commonly, this kind of downconverting nanoparticle combines rare-earth ions and an inorganic crystalline host lattice (e.g., $\mathrm{NaYF}_{4}, \mathrm{NaLuF}_{4}$, and $\mathrm{CaF}_{2}$ ). The host can also provide an environment for energy transfer from a sensitizer to a rare-earth dopant resulting in NIR-II fluorescence.

This review mainly introduces the recent advances in RENPs fluorescent imaging in the NIR-II region. In particular, we focus on the modification of these nanoparticles by lipids or dyes, and their use in cancer diagnosis and therapy. Then, the challenges and prospects of RENPs are discussed.

\section{MAIN KINDS OF RENPS}

Based on the energy level of the rare earth elements, most RENPs possess upconversion and downconversion properties. Up to date, thanks to the effort of many researchers, five of them are reported and extensively explored as activators emitting in NIR-II regions, having excellent downconversion emission $\left(1,060 / 1,300 \mathrm{~nm}\right.$ for $\mathrm{Nd}^{3+}, 1,470 \mathrm{~nm}$ for $\mathrm{Tm}^{3+}, 1,310 \mathrm{~nm}$ for $\mathrm{Pr}^{3+}, 1,185 \mathrm{~nm}$ for $\mathrm{Ho}^{3+}$, and $1,525 \mathrm{~nm}$ for $\mathrm{Er}^{3+}$ ) (Liu et al., 2016) (Figure 2).

\section{Nd-Doped Nanoparticles}

According to recent studies, $\mathrm{Nd}^{3+}$ has gained attention for bioimaging applications due to its special illumination at $808 \mathrm{~nm}$ and deep tissue penetration (Wang et al., 2013). With strong absorption at $730 \mathrm{~nm}, 808 \mathrm{~nm}$ or $860 \mathrm{~nm}, \mathrm{Nd}^{3+}$ can transfer photons with the generation of electrons from the ${ }^{4} \mathrm{I}_{9 / 2}$ ground state to the ${ }^{4} \mathrm{~F}_{7 / 2},{ }^{4} \mathrm{~F}_{5 / 2}$, or ${ }^{4} \mathrm{~F}_{3 / 2}$; then the electrons move back to the ${ }^{4} \mathrm{~F}_{3 / 2}$ state, which can reduce the overheating effect of tissues usually caused by $980 \mathrm{~nm}$ light. As a result of the two transitions, the emission corresponds to $1,060 \mathrm{~nm}\left({ }^{4} \mathrm{~F}_{3 / 2} \rightarrow{ }^{4} \mathrm{I}_{11 / 2}\right)$ and $1,330 \mathrm{~nm}\left({ }^{4} \mathrm{~F}_{3 / 2} \rightarrow{ }^{4} \mathrm{I}_{13 / 2}\right)$ in the NIR-II region. Thus, it provides a good way to avoid autofluorescence of tissue.

Earlier attempts of using $\mathrm{Nd}$-doped nanomaterials as NIRII biomedical imaging agents have been described (Villa et al., 2015; Yu et al., 2018). In 2002, Stouwdam et al. first realized that $\mathrm{Nd}^{3+}$ doped $\mathrm{LaF}_{3}$ nanoparticles can be utilized as a 
polymer-based optical component under $514 \mathrm{~nm}$ laser excitation (Stouwdam and van Veggel, 2002). Then, Wang et al. developed the synthesized method of $\mathrm{LaF}_{3}: \mathrm{Nd}^{3+}$. It was carried out in aqueous solution at low temperature, and showed great NIR-II emission under $802 \mathrm{~nm}$ laser excitation (Wang et al., 2006). In 2014, $\mathrm{LaF}_{3}: \mathrm{Nd}^{3+}$ nanoparticles were used to obtain both in vitro and in vivo images in cancer cells and mice by Rocha et al. The results showed that $\mathrm{LaF}_{3}: \mathrm{Nd}^{3+}$ nanoparticles are a very promising fluorescent nanoprobe for bioimaging in the second NIR window (Rocha et al., 2014). One year later, Villa and his group did an exciting work on high-contrast in vivo imaging in the second biological window (Villa et al., 2015). This work showed how to produce autofluorescence free, high contrast in vivo fluorescence imaging with $1340 \mathrm{~nm}$ emission band of $\mathrm{SrF}_{2}$ : $\mathrm{Nd}^{3+}$ nanoparticles. They found that autofluorescence of animal diet can extend up to about $1,100 \mathrm{~nm}$, which demonstrated that food-related infrared autofluorescence has an impact on the study of reliable biodistribution. In the past 3 years, some new host matrices have been reported, such as $\mathrm{LiYF}_{4}$ (Jiang et al., 2016), $\mathrm{GdPO}_{4}$ (Yang et al., 2018), $\mathrm{CaTiO}_{3}$ (Li et al., 2015), and $\mathrm{NaDyF}_{4}$ (Liu et al., 2017). As we know, higher $\mathrm{Nd}^{3+}$ doping will result in severe quenching of concentration, so to induce great fluorescence signals, the concentration of $\mathrm{Nd}^{3+}$ should be controlled between 1 and $5 \%$. Thanks to intensive research, most of these new $\mathrm{Nd}^{3+}$ doped systems are nowadays not only used in vivo NIR-II imaging but also in X-ray CT bioimaging or MRI. Owing to the large X-ray absorption coefficient of $\mathrm{Gd}^{3+}, \mathrm{Dy}^{3+}$, dual-mode molecular imaging has become a new trend in bioimaging, such as NIR-II imaging/CT, NIR-II imaging/MRI, NIR-II imaging/PET.

Despite the efforts made so far as seen above, low optical effects are still a major drawback. However, sensitizers and coreshell structures that can be used to increase the signal-to-noise ratio are gradually becoming more known in the field of NIRII bioimaging, disease detection and treatment. For example, $\mathrm{NaGdF}_{4}: \mathrm{Nd}^{3+}, \mathrm{Yb}^{3+}, \mathrm{Tm}^{3+}$ is a novel nanomaterial which uses $\mathrm{Gd}^{3+}$ as bridge ions and finally traps energy by the initial activator ions $\left(\mathrm{Nd}^{3+}\right)$ (Zhang et al., 2015). Other previous studies also showed that co-doping with $\mathrm{Y}^{3+}$ effectively reduced the aggregation of $\mathrm{Nd}^{3+}$ in $\mathrm{CaF}_{2}$, resulting in a greater luminescence enhancement of $\mathrm{Nd}^{3+}$ (Yu et al., 2018). Chen et al. synthesized high quantum yield core/shell $\mathrm{NaGdF}_{4}$ : 3\% $\mathrm{Nd}^{3+} @ \mathrm{NaGdF}_{4}$ nanoparticles with an average size of $15 \mathrm{~nm}$. An in vitro and in vivo NIR-II bioimaging was obtained by loading HeLa cells with $\mathrm{NaGdF}_{4}: 3 \% \mathrm{Nd}^{3+} @ \mathrm{NaGdF}_{4}$ nanoparticles and transferring $\mathrm{NaGdF}_{4}: 3 \% \mathrm{Nd}^{3+} @ \mathrm{NaGdF}_{4}$ nanoparticles in a nude mouse model (Chen et al., 2012). $\mathrm{CaF}_{2}$ was also used as the shell material to make NaYF4: Yb, Nd@CaF 2 core/shell nanoparticles, which resulted in high contrast multiplexed in vivo imaging in the NIR-II region (Ortgies et al., 2018). In 2018, inspired by Chen's work, Wang et al. fabricated $\mathrm{NaGdF}_{4}: 5 \% \mathrm{Nd}^{3+} @ \mathrm{NaGdF}_{4}$ by the successive layer-by-layer (SILAR) method. To obtain DCNPs-L1-FSH $\beta$ nanoprobes via an EDC/NHS reaction, imageguided surgery for metastatic ovarian cancer could be improved. Utilizing these novel nanoprobes, metastases with $\leq 1 \mathrm{~mm}$ can be completely resected under the guidance of NIR-II imaging
(Wang P. et al., 2018). A recent report showed that the ultra-small $\mathrm{NaGdF}_{4}: 5 \% \mathrm{Nd} @ \mathrm{NaGdF}_{4}(4.38 \pm 0.57 \mathrm{~nm})$ nanoparticles can be applied in the precise inflammation bioimaging by ROS (reactive oxygen species)-responsive cross-linking after modification with GSH (Glu-Cys-Gly) (Wang et al., 2014; Zhao et al., 2019). An interesting work based on supramolecular selfassembly strategy is developed for NIR-II imaging assembly and disassembly through $\mathrm{NaGdF}_{4}: 10 \% \mathrm{Y}, 25 \% \mathrm{Yb}, 0.5 \% \mathrm{Tm} @ \mathrm{NaGdF}_{4}$ UCNP@azobenzene and $\mathrm{NaGdF}_{4}$ : 5\%Nd@NaGdF 4 DCNP@ßcyclodextrin. The new strategy allows flexible assembly and disassembly of nanoparticles by controlling different NIR-lasers, which can reduce the background of biological imaging and long-term cytotoxicity, while providing technical support for further accurate image-guided tumor surgery (Zhao M. et al., 2018). As only a few NIR-II fluorophores can be used directly for bone imaging without linking to targeted ligands, $\mathrm{He}$ et al. demonstrated DSPE-mPEG encapsulated with $\beta$-phase $\mathrm{NaYF}_{4}$ : $7 \% \mathrm{Nd} @ \mathrm{NaYF}_{4}$ can be used for bone and vascular imaging, even real-time image-guided lymph node mapping and resection $(\mathrm{He}$ et al., 2019) (Table 1).

\section{Er-Doped Nanoparticles}

With the rapid development of the RENPs, $\mathrm{Er}^{3+}$ doped nanoprobes are mainly synthesized as upconversion nanomaterials and applied in the VIS and NIR-I regions. In 2011, $\mathrm{Y}_{2} \mathrm{O}_{3}$ : $\mathrm{Yb}$, Er nanoparticles modified by PEG-b-PVBP and PEG- $\mathrm{PO}_{3} \mathrm{H}_{2}$ showed NIR emission at $1,550 \mathrm{~nm}$ in organs of live mice (Kamimura et al., 2011). Then people considered $\mathrm{Er}^{3+}$ as a better dopant since it can exhibit strong downconversion luminescence in NIR-IIb region. Nanoprobes employed in the NIR-IIb region are better for bioimaging, owing to their deeper tissue penetration, higher spatial and temporal resolution and lower autofluorescence than those in the NIR-IIa region; but rare-earth based nanoprobes with high spatial and temporal resolution imaged in NIR-IIb region are still very scarce. There is no doubt that the special characteristic of $\mathrm{Er}^{3+}$ solves the main problem that has plagued researchers for a long time. Two years later, Naczynski et al. first used $\mathrm{NaYF}_{4}$ : Yb, Ln (Ln: Er, Ho, $\mathrm{Tm}$ or $\mathrm{Pr}$ ) for in vivo imaging of tumors. They demonstrated that $\mathrm{Er}^{3+}$ doped nanoprobes were the brightest one. Especially, by encapsulating RENPs with albumin, they provided a good method to improve tumor accumulation (Naczynski et al., 2013). Then, $\mathrm{Er}^{3+}$ codoped $\mathrm{Yb}^{3+}$ nanoprobes have attracted increasing attention due to their special application potential. Polyacrylic acid (PAA) modified $\mathrm{NaYF}_{4}$ : Gd/Yb/Er nanoprobes have been synthesized and have opened the opportunities for NIR-IIb in vivo imaging, non-invasive brain vessel imaging and tiny tumor detection guided by optical imaging (Xue et al., 2018). In 2016, Dang et al. used the well-established technology, Layer-by-Layer (LbL) to design a NIR-II based theranostic platform by $\mathrm{NaYF}_{4}$ : Yb, Er-PLA/DXS/PLA/HA nanoprobes, which can accumulate in diseased sites and demonstrate diagnostic capabilities within an ovarian tumor mouse model. This study demonstrated that these nanoprobes can serve as a promising theranostic platform to monitor the progression and treatment of serous ovarian cancer (Dang et al., 2016). Indeed, core-shell is well known for its unique ability to enhance the $\mathrm{Er}^{3+}$ emission at NIR-II region. 
TABLE 1 | Typical of Nd-RENPs NIR-II nano-composites.

\begin{tabular}{|c|c|c|c|c|}
\hline NIR-II compositions & $\begin{array}{c}\text { Excitation } \\
\text { wavelength } \\
\text { (nm) }\end{array}$ & $\begin{array}{l}\text { Emission wavelength } \\
\qquad(\mathrm{nm})\end{array}$ & Ligands & Applications \\
\hline $\mathrm{SrF}_{2}: \mathrm{Nd}^{3+}$ & 808 & $900-1,500$ & - & In vitro and in vivo NIR-II imaging \\
\hline $\mathrm{CaF}_{2}: \mathrm{Y}^{3+}, \mathrm{Nd}^{3+}$ & 808 & 1,058 & - & In vivo NIR-II imaging \\
\hline $\mathrm{LaF}_{3}: \mathrm{Nd}^{3+}$ & 808 & $910,1,050,1,330$ & - & In vitro and in vivo NIR-II imaging \\
\hline $\mathrm{LiYF}_{4}: 5 \% \mathrm{Nd}^{3+}$ & 808 & $900,1,050,1,330$ & EDTMP & Bio-imaging and biodetection \\
\hline $\mathrm{GdPO}_{4}: \mathrm{Nd}^{3+}$ & 808 & $1,050,1,330$ & DOX & $\begin{array}{l}\text { Dual-modal in vivo NIR-II/X-ray bioimaging and } \\
\text { pH-responsive drug delivery }\end{array}$ \\
\hline $\mathrm{NaDyF}_{4}: 10 \% \mathrm{Nd}$ & 808 & $1,050,1,330$ & Gallic acid-Fe(III) & NIR-II imaging, MRI imaging, PTT \\
\hline $\mathrm{NaGdF}_{4}: \mathrm{Nd}^{3+}, \mathrm{Yb}^{3+}, \mathrm{Tm}^{3+}$ & 800 & $980,1,060$ & - & NIR-II imaging, MRI imaging \\
\hline $\mathrm{NaGdF}_{4}: \mathrm{Nd}^{3+} @ \mathrm{NaGdF}_{4}$ & $740 / 900$ & $1,050,1,300$ & - & In vitro and in vivo NIR-II imaging \\
\hline $\mathrm{NaYF}_{4}: \mathrm{Yb}, \mathrm{Nd} @ \mathrm{CaF}_{2}$ & 808 & $980,1,350$ & Poly(acrylic acid) & Lifetime-gated in vivo multiplexed imaging \\
\hline $\mathrm{NaGdF}_{4}: 5 \% \mathrm{Nd} @ \mathrm{NaGdF}_{4}$ & 808 & 1060 & $\begin{array}{l}\text { DSPE-PEG-NH2-DNA- } \\
\text { FSH } \beta\end{array}$ & $\begin{array}{l}\text { Image-guided surgery for metastatic ovarian } \\
\text { cancer }\end{array}$ \\
\hline 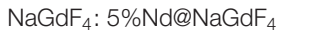 & 808 & - & GSH (Glu-Cys-Gly) & In vivo inflammation Imaging \\
\hline$\beta-\mathrm{NaYF}_{4}: 7 \% \mathrm{Nd} @ \mathrm{NaYF} 4$ & 808 & 1064,1345 & DSPE-mPEG & $\begin{array}{l}\text { NIR-II imaging of bone, vascular tissue and } \\
\text { thrombi }\end{array}$ \\
\hline
\end{tabular}

This special structure does not only delay the degradation of dopant but also decreases the quenching effects and strengthens fluorescence. Simple $\mathrm{NaYF}_{4}$ : Yb/Er@NaYF 4 nanoprobes have been prepared to realize real-time surveillance of metastatic lesions (Kantamneni et al., 2017). Deng et al. proposed Sc-based probes $\left(\mathrm{KSc}_{2} \mathrm{~F}_{7}: \mathrm{Yb}^{3+} / \mathrm{Er}^{3+}\right)$, which are significantly different from the traditional $\mathrm{NaYF}_{4}$ host. After modification with PAA, they showed a $\sim 1.70$-fold stronger fluorescence than the PAA$\mathrm{NaYF}_{4}$ nanocrystals under $980 \mathrm{~nm}$ excitation. On this basis, they performed the first case of through-skull fluorescence imaging of brain vessels with $\mathrm{KSc}_{2} \mathrm{~F}_{7}: \mathrm{Yb}^{3+} / \mathrm{Er}^{3+}$ probes (Deng et al., 2018). Normally, $\mathrm{Yb}^{3+}$ can transfer energy to $\mathrm{Er}^{4} \mathrm{I}_{11 / 2}$ level to release non-radiative photons to the ${ }^{4} \mathrm{I}_{13 / 2}$ level, and then radiate to the ${ }^{4} \mathrm{I}_{15 / 2}$ level to produce the $1,550 \mathrm{~nm}$ downconversion emission. During this process, upconversion and quenching effects will decrease the intensity of $\mathrm{Er}^{3+}$ downconversion emission. As an alternative, $\mathrm{Ce}^{3+}$ is developed as a doping element in Er-doped nanoparticles to improve the NIR-II downconversion emission by efficiently accelerating non-radiative relaxation of $\mathrm{Er}^{4} \mathrm{I}_{11 / 2}$

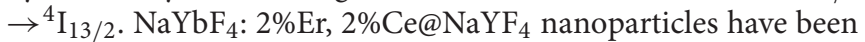
made to prove $\mathrm{Ce}^{3+}$ can highly suppress the upconversion with the downconversion pathway boosted by about 9-fold. This can lead to fast NIR-II cerebral-vasculatures imaging by modified PMF-PEG (Zhong et al., 2017). The synthesis of $\mathrm{NaCeF}_{4}: \mathrm{Er} / \mathrm{Yb} @ \mathrm{NaCeF}_{4}$ has further verified the efficient energy transfer of $\mathrm{Yb}^{3+}-\mathrm{Er}^{3+}-\mathrm{Ce}^{3+}$. Surface modification with DSPE-PEG2000-COOH proved to be a useful method to detect uric acid and can be a key approach in a physiological survey and clinical diagnosis (Lei et al., 2018). Interesting research has been done to design and implant $\mathrm{QR}$ codes into a mouse by incorporating $\mathrm{NaYF}_{4}: \mathrm{Tm}^{3+} / \mathrm{Er}^{3+} @ \mathrm{NaYF}_{4}$ into polydimethylsiloxane (PDMS) matrices. The QR code consists of black squares arranged in a square grid on a white background according to certain rules, and the imaging device can read the data from the horizontal and vertical components of the image. It provides a possibility for NIR-II in vivo information storage and decoding (Zhang et al., 2019). A core/multishell structure $\left(\mathrm{NaGdF}_{4} @ \mathrm{NaGdF}_{4}: \mathrm{Yb} / \mathrm{Er} @ \mathrm{NaYF}_{4}: \mathrm{Yb} @ N a N d F_{4}: \mathrm{Yb}\right)$ has also been used for breast cancer diagnostics in vivo (Fan et al., 2018). Recent progress has focused on the diversification of Er-doped rare-earth nanoparticles. $\mathrm{NaYF}_{4}$ : Er nanoparticles conjugated with the indocyanine green dye (ICG) have been applied to bioimaging in the NIR-II window because of their high spatial resolution. Due to high absorption cross-section of ICG, excitation efficiency of $\mathrm{Er}^{3+}$ is increased by the energy transfer mechanism and has proved the potential of ICG-NaYF 4 : Er nanoconjugates for multimodal theranostics (Wang D. et al., 2018) (Figure 3). Since NIR-II imaging-guided photothermal therapy (PTT) is rarely explored, Liu et al. have successfully developed a core-shell structured $\mathrm{NaLuF}_{4}: \mathrm{Gd} / \mathrm{Yb} / \mathrm{Er}$ NRs@PDA as a nanoplatform that can simultaneously be used to diagnose and treat tumors. It can not only be used to realize NIR-II imaging but also to enable image-guided PTT (Li X. et al., 2019).

\section{SYNTHESIS AND MODIFICATION}

At present, RENPs are synthesized by a solvothermal method, which is technically mature. Solvothermal synthesis is a solution chemistry method that crystallizes nanomaterials of different sizes and morphologies directly from solution under a certain temperature and pressure. To synthesize RENPs with uniform size and morphology, good dispensability and high luminous efficiency, the size and morphology have to be controlled by adjusting the ratio of raw materials, temperature and solvents (Mai et al., 2007; Zhang et al., 2007; Tan et al., 2009, 2013; Wang et al., 2010; Yuan et al., 2013). On the other hand, because this process cannot precisely control the distribution 


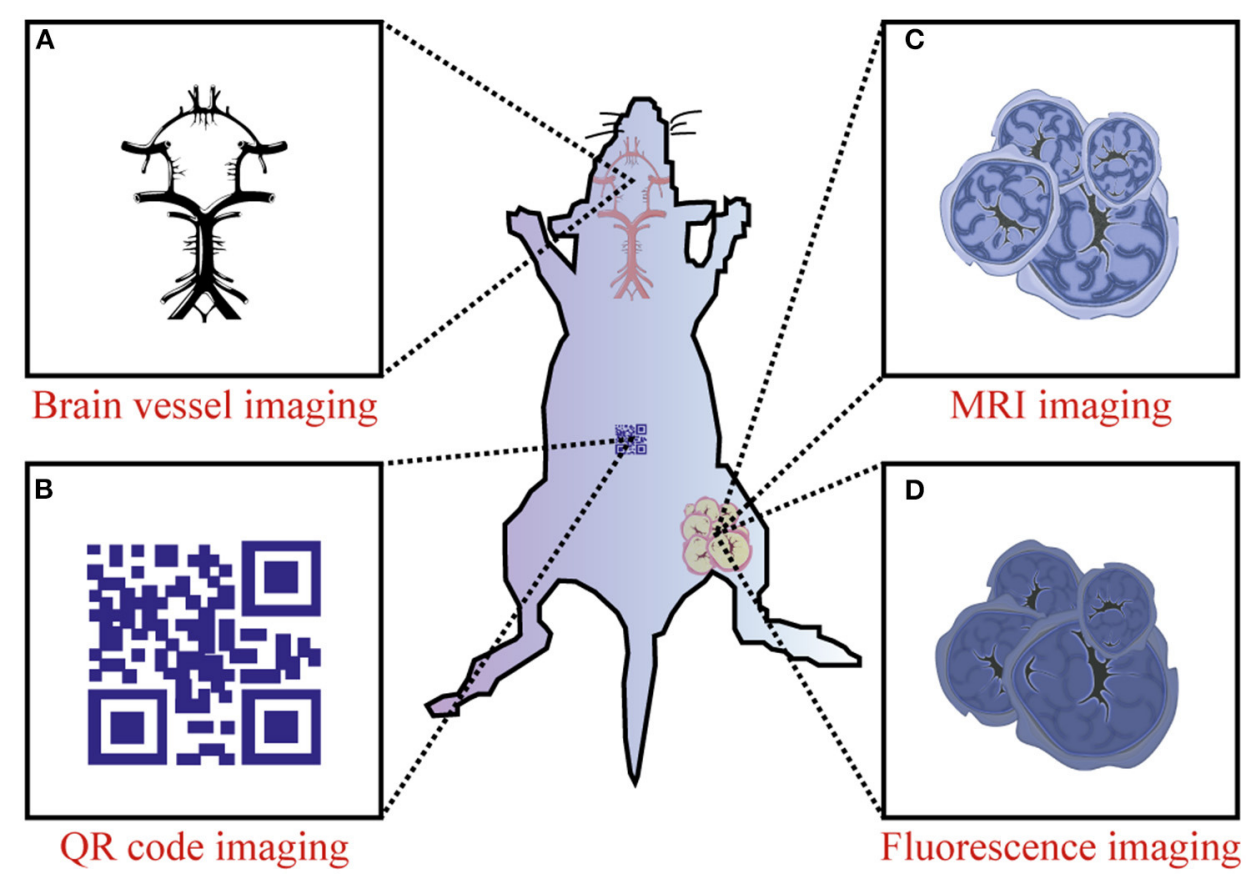

FIGURE 3 | Preclinical application of Er-RENPs in the NIR-II region. (A) NIR-II brain vessel imaging, (B) NIR-II QR code imaging and (C,D) dual mode MRI imaging/ NIR-II fluorescence imaging.

of dopants, the local relative enrichment of the dopants usually occurs, resulting in the reduction of luminescent efficiency. In order to avoid the deficiency, one pot successive layer-by-layer (SLBL) strategy is used to synthesize homogeneous doping core (HOC) nanoparticles by growing uniform shells (Li X. et al., 2014, 2019). However, RENPs prepared with oleic acid as reagent are hardly soluble in water and difficult to attach to biomolecules. This limits their application in cell labeling and fluorescent imaging. It is therefore necessary to convert a hydrophobic group into a hydrophilic group by surface modification (for example, $-\mathrm{COOH},-\mathrm{NH}_{2}$, or $-\mathrm{SH}$ ). Alternatively, Dong et al. have reported the oleate ligands attached to the UCNPs surface can be replaced by nitrosonium tetrafluoroborate $\left(\mathrm{NOBF}_{4}\right)$ (Dong et al., 2011). Currently, the main surface modification methods used are ligand oxidation, ligand exchange and layerby-layer self-assembly (Wang and Liu, 2009; Li and Lin, 2010). The nanoparticle size does not increase after the water-soluble modification using the ligand exchange method, and it is not easy to control the exchange efficiency and effect of water solubility. After using ligand oxidation for modification, due to the shortening of the ligand carbon chain, polar solvent water cannot be effectively suppressed not to quench the fluorescence, and also the fluorescence intensity is much weaker. This method is only suitable for the oxidation of ligands containing carbon-carbon double bonds $(\mathrm{C}=\mathrm{C})$. Therefore, it is still a hot Research Topic to select effective water-soluble modification methods to obtain RENPs with small particle size, good water solubility and high fluorescence intensity. The following is a brief summary to the currently used surface modification methods (Figure 4).

\section{Ligand Oxidation}

The ligand oxidation method requires a strong oxidizing agent (Lemieux-von Rudloff reagent, etc.) to oxidize the carbon-carbon double bond to a carboxyl group, which is on the surfacecoated oleic acid ligand. This reaction can obtain hydrophilic, carboxylic acid-functional RENPs. Thus, the RENPs not only have good water solubility, but also can be directly coupled with diverse biomolecules.

\section{Ligand Exchange}

The ligand exchange method is used to replace an organic ligand having weak coordination and hydrophobicity with a strong hydrophilic organic ligand on the surface of the material. This process makes the RENPs hydrophilic and water-soluble.

\section{Layer-by-Layer Self-Assembly Method}

The principle of the layer-by-layer self-assembly method (Wang et al., 2002) is to first wrap a layer of polymer compound with a certain charge on the surface of hydrophobic RENPs. When it is added to a solution of an opposite charged polymer compound, another opposite charged polymer compound can be attracted to the first layer. In this way, the layers are adsorbed, and the upper fluorescent group can be converted, which is possible by alternating self-assembled layers into a polymer layer on the surface of the RENPs. The thickness of the polymer layer can be regulated by changing the number of self-assembled layers so that the RENPs can be stably dispersed in water and have good biocompatibility. 


\section{A Ligand oxidation}

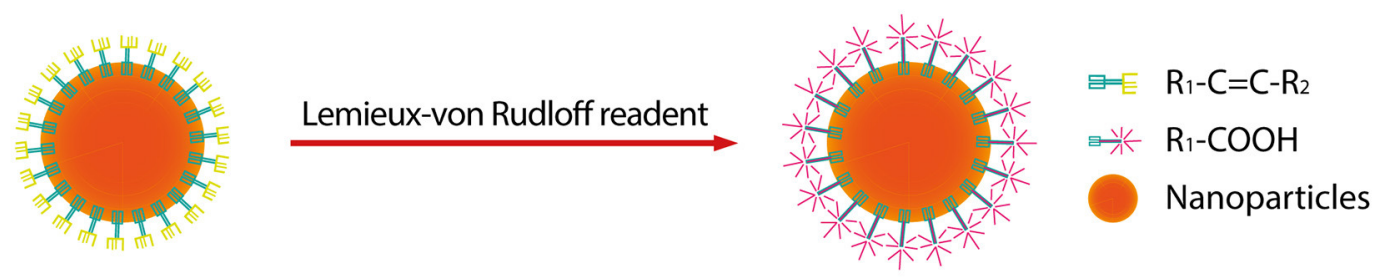

B Ligand exchange

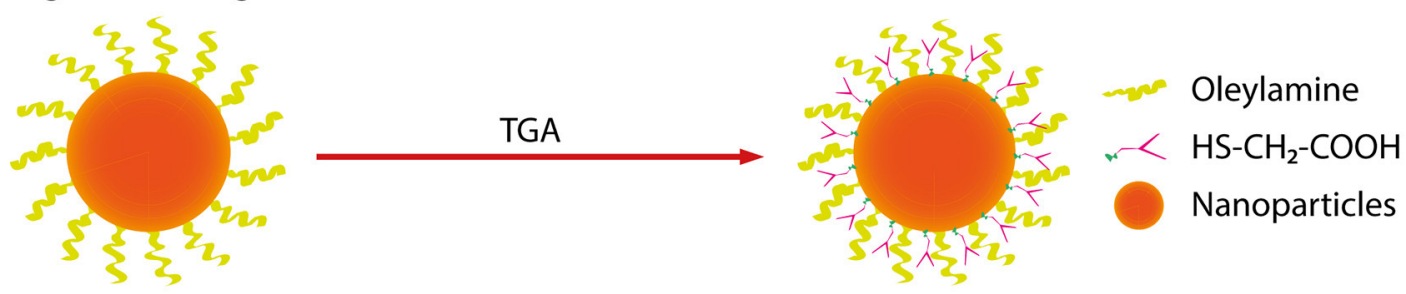

c Layer-by-layer self-assembly method
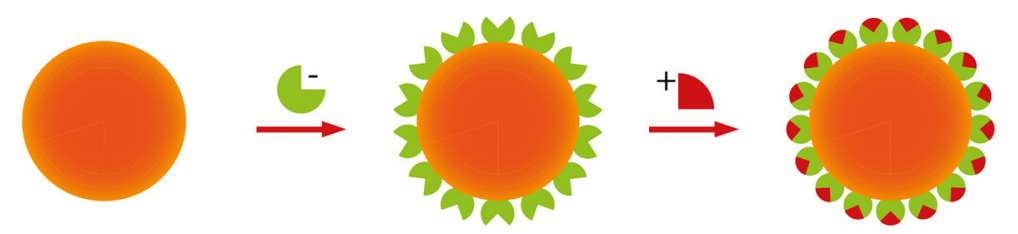

Nanoparticles

Negative polymer compound

Positive polymer compound

FIGURE 4 | Surface modification methods of RENPs. (A) The ligand oxidation method requires a strong oxidizing agent (Lemieux-von Rudloff reagent, etc.) to oxidize the carbon-carbon double bond to a carboxyl group. (B) The ligand exchange method is used to replace an organic ligand having weak coordination and hydrophobicity with a strong hydrophilic organic ligand. (C) The layer-by-layer self-assembly method relies mainly on the attractive force between oppositely charged molecules, alternately deposits dense monolayers of charged molecules onto oppositely charged surfaces.

\section{CANCER THERANOSTICS WITH NIR-II RENPs}

Currently, clinically approved indocyanine green (ICG) and methylene blue $(\mathrm{MB})$ have been used as contrast agents to depict tumor margins in preclinical cancer models and human patients (Winer et al., 2010; Vahrmeijer et al., 2013; Wang et al., 2015). However, these rapidly excreted probes possess short tumor retention times and affect the process of cancer treatment. Due to the renal filtration threshold of $\sim 40 \mathrm{kD}$, most fluorescent probes accumulate largely in the organs of reticuloendothelial system, such as the liver and spleen, leading to long-term safety concerns. Therefore, NIRII RENPs probes with long tumor retention times, high signalto-background ratio and deep tissue penetration have aroused great interest in investigating their applications for cancer theranostics. To reduce the retention time of nanoparticles in the reticuloendothelial system, excretable NIR-II nanoparticles, RENPs@Lips, have been developed for medical imaging and surgical navigation. Under the guidance of NIR-II imaging, RENPs@Lips showed excellent performance in intraoperative identification of orthotopic tumor vessels and embolization surgery, and could be used in sentinel lymph node biopsies in tumor-bearing mice (Li D. et al., 2019). CXCR-4-targeted functional nanoprobes (fReANC) have been demonstrated to detect up to $10.5 \mathrm{~mm}$ of deep-seeded subtissue microlesions in lung metastatic models of breast cancer, providing a reliable platform for the detection of targeted subtissue cancerous lesions (Zevon et al., 2015). At the same time, Dang et al. compared several available LbL NIR-II probes, found that rare-earth-based down-conversion nanoparticles can define vascular and skeletal structures, and were evaluated as diagnostic probes for highgrade serous ovarian cancer with the highest resolution out of all tested probes (Dang et al., 2016). NIR-II RENPs, with the least interference from scattering and autofluorescence, seemed to represent a promising tool for photothermal therapy (PTT) and photodynamic therapy (PDT). He et al. have designed a unique $\mathrm{NaGdF}_{4}: \mathrm{Nd@NaGdF} \mathrm{NaGdF}_{4}$ : $\mathrm{Yb}, \mathrm{Nr} @ \mathrm{NaGdF}_{4}$ : $\mathrm{Yb} @ \mathrm{NaNdF}_{4}: \mathrm{Yb}$ (LDNPs-5) structure by attaching Au25 clusters and poly(ethylene glycol) (PEG) molecules on nanostructure. Under $808 \mathrm{~nm}$ light irradiation, the special LDNPs can efficiently kill tumor cells in vitro and in vivo due to a synergistic effect arising from the combination of PTT effect generated from $\mathrm{Nd}^{3+}$ with PDT (He et al., 2016). In addition, a three-layer core-shellshell nanocomposite $\left(\mathrm{NaYF}_{4}: \mathrm{Nd}^{3+} @ \mathrm{NaLuF}_{4} @ \mathrm{PDA}_{18}\right)$ showed an excellent PTT effect in ablation tumors (Dai et al., 2017). Recently, dual-mode SWIR imaging and MRI guided PTT was performed in a nude mouse model by using $\mathrm{NaErF}_{4} @ \mathrm{NaGdF}_{4}$ (Er@Gd), which can effectively be used to ablate tumors and provide a new way for cancer theranostics (Ma et al., 2018). 
$\mathrm{NaErF}_{4} @ \mathrm{NaYF}_{4} @ \mathrm{NaNdF}_{4} @$ Prussian blue $(\mathrm{PB})$ encapsulated in a phospholipid PEG micelle (PEG-CSS@PB) served as an efficient theranostic agent for NIR-II-image guided PTT. In this study, tumors treated with PTT shrank $\sim 12$-fold compared with untreated tumors (Wang et al., 2019c). To achieve accurate tumor localization and a high cancer therapeutic efficacy, Liu et al. developed an ultrasmall $\mathrm{pH}$-responsive photothermal gallic acid-iron complex-modified $\mathrm{NaDyF}_{4}$ : $\mathrm{Nd}$ nanoprobe to enhance cancer theranostic by in situ aggregation (Liu et al., 2017). In addition, a theranostic nanoparticle based on RENPs has been developed for gene therapy. Polyethylenimine (PEI) coated $\beta$ $\mathrm{NaY}_{0.78} \mathrm{~F}_{4}: \mathrm{Yb}_{0.20}, \mathrm{Er}_{0.02} @ \mathrm{NaYF}_{4}$ was designed to deliver genetic cargo in an in vitro cancer model and detected tumor lesions in a lung metastases model of breast cancer. This strategy will make it possible to develop a nanotheranostic platform based on NIRII RENPs for gene therapy (Zhao Z. et al., 2018). In summary, NIR-II RENPs have great potential in cancer theranostics.

\section{DISCUSSION}

Overall, RENPs are promising candidates for NIR-II biomedical imaging due to their low toxicity, high photostability, deep tissue penetration, and tunable pharmacokinetic behavior. Despite these successful gains, challenges still remain in the bioimaging applications of NIR-II RENPs. One of them is the limitation of the emission center, which is the fluorescence core of the RENPs. As we know, five rare earth elements $\left(\mathrm{Nd}^{3+}, \mathrm{Tm}^{3+}, \mathrm{Pr}^{3+}, \mathrm{Ho}^{3+}\right.$, $\mathrm{Er}^{3+}$ ) can be the emission centers in NIR-II RENPs, which are excited by $808 \mathrm{~nm}$ or $980 \mathrm{~nm}$ lasers. However, the RENPs that have been developed are still mainly based on $\mathrm{Nd}^{3+}$ and $\mathrm{Er}^{3+}$ as the emission centers, which greatly limits the development and application of near-infrared probe types. Although other rare earth elements have also been presented, such efforts should be devoted to design novel NIR-II RENPs probes. For example, Liu et al. used $\mathrm{Er}^{3+}$ as a sensitizer and $\mathrm{Ho}^{3+}$ as an emitter to make a core-shell structured $\mathrm{NaErF}_{4}$ : Ho@NaYF 4 nanoparticle, which emitted at 1,180 nm (Liu et al., 2018). Besides that, the size of the RENPs has always been a concern in bioimaging. Smaller size

\section{REFERENCES}

Chen, G., Ohulchanskyy, T. Y., Liu, S., Law, W. C., Wu, F., Swihart, M. T., et al. (2012). Core/shell $\mathrm{NaGdF}_{4}: \mathrm{Nd}^{3+} / \mathrm{NaGdF}_{4}$ nanocrystals with efficient nearinfrared to near-infrared downconversion photoluminescence for bioimaging applications. ACS Nano. 6, 2969-2977. doi: 10.1021/nn2042362

Dai, Y., Yang, D., Yu, D., Cao, C., Wang, Q., Xie, S., et al. (2017). Musselinspired polydopamine-coated lanthanide nanoparticles for NIR-II/CT dual imaging and photothermal therapy. ACS Appl. Mater. Interf. 9, 26674-26683. doi: 10.1021/acsami.7b06109

Dang, X., Gu, L., Qi, J., Correa, S., Zhang, G., Belcher, A. M., et al. (2016). Layerby-layer assembled fluorescent probes in the second near-infrared window for systemic delivery and detection of ovarian cancer. Proc. Natl. Acad. Sci U.S.A. 113, 5179-5184. doi: 10.1073/pnas.1521175113

Deng, Z., Li, X., Xue, Z., Jiang, M., Li, Y., Zeng, S., et al. (2018). A high performance sc-based nanoprobe for through-skull fluorescence imaging of brain vessels beyond $1500 \mathrm{~nm}$. Nanoscale 10, 9393-9400. doi: 10.1039/C8NR00305J

Dong, A., Ye, X., Chen, J., Kang, Y., Gordon, T., Kikkawa, J. M., et al. (2011). A generalized ligand-exchange strategy enabling sequential surface nanoparticles can effectively enter biological tissues, even cells, but the luminescence intensity of nanomaterials will decrease. Although the commonly used core-shell structure can enhance the luminescence intensity, it will increase the size, making it difficult for the nanoparticles to gain entry into biological tissues and the digestion time will become longer. Designing suitable size nanoparticles is still an essential task to promote the NIR-II bioimaging applications of RENPs. All of these studies in the past decades have pointed out that RENPs will play an important role in drug delivery tracking and multispectral molecular imaging in the near future.

\section{AUTHOR CONTRIBUTIONS}

ZY, CE, and LC structured the review. ZY wrote the review. CE and LC revised the text. All authors contributed to the article and approved the submitted version.

\section{FUNDING}

ZY was supported by the CSC scholarship. CE was supported by the research program VENI with project number 916.181.54, which is (partly) financed by the Dutch Research Council (NWO). LC was supported by project grants from the European Commission H2020-MSCA-RISE (644373-PRISAR), H2020-MSCA-RISE (777682-CANCER), H2020-WIDESPREAD-05-2017-Twinning (807281-ACORN), H2020-WIDESPREAD-2018-03 (852985-SIMICA), H2020SCA-RISE-2016 (734684-CHARMED), and MSCA-ITN-2015ETN (675743-ISPIC), 861190 (PAVE), 857894 (CAST), 859908 (NOVA-MRI); 860173 (RISE-WELL); 872860 (PRISAR2) and research program VIDI (project number 723.012.110) of Dutch Research Council (NWO).

\section{ACKNOWLEDGMENTS}

We would like to thank E. L. Kaijzel for proof-reading of the manuscript. functionalization of colloidal nanocrystals. J. Am. Chem. Soc. 133, 998-1006. doi: $10.1021 /$ ja108948z

Dong, H., Du, S. R., Zheng, X. Y., Lyu, G. M., Sun, L. D., Li, L. D., et al. (2015). Lanthanide Nanoparticles: from Design toward Bioimaging and Therapy. Chem. Rev. 115, 10725-10815. doi: 10.1021/acs.chemrev.5b00091

Fan, Y., Wang, P., Lu, Y., Wang, R., Zhou, L., Zheng, X., et al. (2018). Lifetimeengineered NIR-II nanoparticles unlock multiplexed in vivo imaging. Nat. Nanotechnol. 13, 941-946. doi: 10.1038/s41565-018-0221-0

Fan, Y., Wang, S., and Zhang, F. (2019). Optical multiplexed bioassays for improved biomedical diagnostics. Angew. Chem. Int. Ed. 58, 13208-13219. doi: $10.1002 /$ anie. 201901964

Fan, Y., and Zhang, F. (2019). A new generation of NIR-II probes: lanthanidebased nanocrystals for bioimaging and biosensing. Adv. Opt. Mater. 7:1801417.doi: 10.1002/adom.201801417

Gong, H., Peng, R., and Liu, Z. (2013). Carbon nanotubes for biomedical imaging: the recent advances. Adv. Drug Deliv. Rev. 65, 1951-1963. doi: 10.1016/j.addr.2013.10.002

He, F., Feng, L., Yang, P., Liu, B., Gai, S., Yang, G., et al. (2016). Enhanced up/downconversion luminescence and heat: simultaneously achieving in one single 
core-shell structure for multimodal imaging guided therapy. Biomaterials.105, 77-88. doi: 10.1016/j.biomaterials.2016.07.031

He, S., Chen, S., Li, D., Wu, Y., Zhang, X., Liu, J., et al. (2019). High affinity to skeleton rare earth doped nanoparticles for near-infrared II imaging. Nano Lett.19, 2985-2992. doi: 10.1021/acs.nanolett.9b00140

Hemmer, E., Benayas, A., Légar, É, F., and Vetrone, F. (2016). Exploiting the biological windows: current perspectives on fluorescent bioprobes emitting above $1000 \mathrm{~nm}$. Nanoscale Horiz. 1, 168-184. doi: 10.1039/C5NH00073D

Hong, G., Zou, Y., Antaris, A. L., Diao, S., Wu, D., Cheng, K., et al. (2014). Ultrafast fluorescence imaging in vivo with conjugated polymer fluorophores in the second near-infrared window. Nat. Commun. 5, 1-9. doi: 10.1038/ncomms5206

Jiang, X., Cao, C., Feng, W., and Li, F. (2016). $\mathrm{Nd}^{3+}{ }_{-}$-doped $\mathrm{LiYF}_{4}$ nanocrystals for bio-imaging in the second near-infrared window. J. Mater. Chem. B 4, 87-95. doi: $10.1039 /$ С5TB02023A

Kamimura, M., Kanayama, N., Tokuzen, K., Soga, K., and Nagasaki, Y. (2011). Near-infrared $(1550 \mathrm{~nm})$ in vivo bioimaging based on rare-earth doped ceramic nanophosphors modified with PEG-b-poly (4-vinylbenzylphosphonate). Nanoscale 3, 3705-3713. doi: 10.1039/c1nr10466g

Kamimura, M., Matsumoto, T., Suyari, S., Umezawa, M., and Soga, K. K. (2017). Ratiometric near-infrared fluorescence nanothermometry in the OTNNIR (NIR II/III) biological window based on rare-earth doped $\beta-\mathrm{NaYF}_{4}$ nanoparticles, J. Mater. Chem. B 5, 1917-1925. doi: 10.1039/C7TB00070G

Kantamneni, H., Zevon, M., Donzanti, M. J., Zhao, X., Sheng, Y., Barkund, S. R., et al. (2017). Surveillance nanotechnology for multi-organ cancer metastases. Na. Biomed Eng. 1, 993-1003. doi: 10.1038/s41551-017-0167-9

Kuimova, M. K., Botchway, S. W., Parker, A. W., Balaz, M., Collins, H. A., Anderson, H. L., et al. (2009). Imaging intracellular viscosity of a single cell during photoinduced cell death. Nat. Chem. 1, 69-73. doi: 10.1038/nchem.120

Lei, X., Li, R., Tu, D., Shang, X., Liu, Y., You, W., et al. (2018). Intense nearinfrared-II luminescence from $\mathrm{NaCeF}_{4}: \mathrm{Er} / \mathrm{Yb}$ nanoprobes for in vitro bioassay and in vivo bioimaging. Chem. Sci. 9, 4682-4688. doi: 10.1039/C8SC00927A

Lei, Z., Sun, C., Pei, P., Wang, S., Li, D., Zhang, X., et al. (2019). Stable, wavelengthtunable fluorescent dyes in the NIR-II region for in vivo high-contrast bioimaging and multiplexed biosensing. Angew. Chem. 131, 8250-8255. doi: 10.1002 /ange.201904182

Li, C., and Lin, J. (2010). Rare earth fluoride nano-/microcrystals: synthesis, surface modification and application. J. Mater. Chem. 20, 6831-6847. doi: $10.1039 / \mathrm{c} 0 \mathrm{jm} 00031 \mathrm{k}$

Li, C., Zhang, Y., Wang, M., Zhang, Y., Chen, G., Li, L., et al. (2014). In vivo real-time visualization of tissue blood flow and angiogenesis using $\mathrm{Ag}_{2} \mathrm{~S}$ quantum dots in the NIR-II window. Biomaterials 35, 393-400. doi: $10.1016 /$ j.biomaterials.2013.10.010

Li, D., He, S., Wu, Y., Liu, J., Liu, Q., Chang, B., et al. (2019). Excretable lanthanide nanoparticle for biomedical imaging and surgical navigation in the second near-infrared window. Adv. Sci. 6:1902042.doi: 10.1002/advs.201902042

Li, X., Jiang, M., Zeng, S., and Liu, H. (2019). Polydopamine coated multifunctional lanthanide theranostic agent for vascular malformation and tumor vessel imaging beyond $1500 \mathrm{~nm}$ and imaging-guided photothermal therapy. Theranostics. 9:3866. doi: 10.7150/thno.31864

Li, X., Shen, D., Yang, J., Yao, C., Che, R., Zhang, F., et al. (2013). Successive layer-by-layer strategy for multi-shell epitaxial growth: shell thickness and doping position dependence in upconverting optical properties. Chem. Mater. 25, 106-112.doi: $10.1021 / \mathrm{cm} 3033498$

Li, X., Wang, R., Zhang, F., and Zhao, D. (2014). Engineering homogeneous doping in single nanoparticle to enhance upconversion efficiency. Nano Lett. 14, 3634-3639.doi: 10.1021/nl501366x

Li, X., Zhang, Q., Ahmad, Z., Huang, J., Ren, Z., Weng, W., et al. (2015). Nearinfrared luminescent $\mathrm{CaTiO}_{3}: \mathrm{Nd}^{3+}$ nanofibers with tunable and trackable drug release kinetics. J. Mater. Chem. B 3, 7449-7456. doi: 10.1039/C5TB01158B

Liang, C., Diao, S., Wang, C., Gong, H., Liu, T., Hong, G., et al. (2014). Tumor metastasis inhibition by imaging-guided photothermal therapy with single-walled carbon nanotubes. Adv. Mater. 26, 5646-5652. doi: 10.1002/adma.201401825

Liu, L., Wang, S., Zhao, B., Pei, P., Fan, Y., Li, X., et al. (2018). $\mathrm{Er}^{3+}$ sensitized $1530 \mathrm{~nm}$ to $1180 \mathrm{~nm}$ second near-infrared window upconversion nanocrystals for in vivo biosensing. Angew. Chem. Int. Ed. 57, 7518-7522. doi: $10.1002 /$ anie.201802889
Liu, T. M., Conde, J., Lipinski, T., Bednarkiewicz, A., and Huang, C. C. (2016). Revisiting the classification of NIR-absorbing/emitting nanomaterials for in vivo bioapplications. NPG Asia Mater. 8, e295-e295. doi: 10.1038/am.2016.106

Liu, Y., Fan, H., Guo, Q., Jiang, A., Du, X., and Zhou, J. (2017). Ultra-small pHresponsive $\mathrm{Nd}$-doped $\mathrm{NaDyF}_{4}$ nanoagents for enhanced cancer theranostic by in situ aggregation. Theranostics 7:4217. doi: 10.7150/thno.21557

Ma, L., Liu, Y., Liu, L., Jiang, A., Mao, F., Liu, D., et al. (2018). Simultaneous activation of short-wave infrared (SWIR) light and paramagnetism by a functionalized shell for high penetration and spatial resolution theranostics. Adv. Func. Mater. 28:1705057. doi: 10.1002/adfm.201705057

Mai, H. X., Zhang, Y. W., Sun, L. D., and Yan, C. H. (2007). Size-and phasecontrolled synthesis of monodisperse $\mathrm{NaYF}_{4}$ : yb, Er nanocrystals from a unique delayed nucleation pathway monitored with upconversion spectroscopy. $J$. Phys. Chem. C 111, 13730-13739. doi: 10.1021/jp073919e

Mariani, G., Gipponi, M., Moresco, L., Villa, G., Bartolomei, M., Mazzarol, G., et al. (2002). Radioguided sentinel lymph node biopsy in malignant cutaneous melanoma. J. Nucl. Med. 43, 811-827.

Mariani, G., Moresco, L., Viale, G., Villa, G., Bagnasco, M., Canavese, G., et al. (2001). Radioguided sentinel lymph node biopsy in breast cancer surgery. $J$ Nucl. Med. 42, 1198-1215.

Naczynski, D. J., Tan, M. C., Zevon, M., Wall, B., Kohl, J., Kulesa, A., et al. (2013). Rare-earth-doped biological composites as in vivo shortwave infrared reporters. Nat. Commun. 4:2199. doi: 10.1038/ncomms3199

O’Leary, D. H., Polak, J. F., Kronmal, R. A., Manolio, T. A., Burke, G. L., Wolfson, S. K., et al. (1999). Carotid-artery intima and media thickness as a risk factor for myocardial infarction and stroke in older adults. N. Engl. J. Med. 340, 14-22. doi: 10.1056/NEJM199901073400103

Ortgies, D. H., Tan, M., Ximendes, E. C., Del Rosal, B., Hu, J., Xu, L., et al. (2018). Lifetime-encoded infrared-emitting nanoparticles for in vivo multiplexed imaging. ACS Nano.12, 4362-4368. doi: 10.1021/acsnano.7b09189

Paulus, M. J., Gleason, S. S., Kennel, S. J., Hunsicker, P. R., and Johnson, D. K. (2000). High resolution X-ray computed tomography: an emerging tool for small animal cancer research. Neoplasia 2, 62-70. doi: 10.1038/sj.neo.7900069

Quon, A., and Gambhir, S. S. (2005). FDG-PET and beyond: molecular breast cancer imaging. J. Clin. Oncol. 23, 1664-1673. doi: 10.1200/JCO.2005.11.024

Rocha, U., Kumar, K. U., Jacinto, C., Villa, I., Sanz-Rodríguez, F., de la Cruz, M. D. C. I., et al. (2014). Neodymium-doped $\mathrm{LaF}_{3}$ nanoparticles for fluorescence bioimaging in the second biological window. Small 10, 1141-1154. doi: $10.1002 /$ smll.201301716

Rubin, E. H., Allen, J. D., Nowak, J. A., and Bates, S. E. (2014).Developing precision medicine in a global world. Clin. Cancer Res. 20, 1419-1427. doi: 10.1158/1078-0432.CCR-14-0091

Stouwdam, J. W., and van Veggel, F. C. (2002). Near-infrared emission of redispersible $\mathrm{Er}^{3+}, \mathrm{Nd}^{3+}$, and $\mathrm{Ho}^{3+}$ doped LaF3 nanoparticles. Nano Lett. 2, 733-737. doi: $10.1021 / \mathrm{nl} 025562 \mathrm{q}$

Tan, M. C., Kumar, G. A., Riman, R. E., Brik, M. G., Brown, E., and Hommerich, U. (2009). Synthesis and optical properties of infrared-emitting $\mathrm{YF}_{3}$ : $\mathrm{Nd}$ nanoparticles. J. Appl. Phys. 106:063118. doi: 10.1063/1.3168442

Tan, M. C., Naczynski, D. J., Moghe, P. V., and Riman, R. E. E. (2013). Engineering the design of brightly-emitting luminescent nanostructured photonic composite systems. Aust. J. Chem. 66, 1008-1020.doi: 10.1071/CH13221

Toussaint, J. F., Lamuraglia, G. M., Southern, J. F., Fuster, V., and Kantor, H. L. (1996). Magnetic resonance images lipid, fibrous, calcified, hemorrhagic, and thrombotic components of human atherosclerosis in vivo. Circulation 94, 932-938. doi: 10.1161/01.CIR.94.5.932

Tsien, R. Y. (2003). Imagining imaging's future. Nat. Rev. Mol. Cell Biol. (Suppl.). 4:SS16-SS21. doi: 10.1038/nrm1196

Vahrmeijer, A. L., Hutteman, M., Van Der Vorst, J. R., Van De Velde, C. J., and Frangioni, J. V. (2013). Image-guided cancer surgery using near-infrared fluorescence. Nat. Rev. Clin. Oncol. 10, 507-518. doi: $10.1038 /$ nrclinonc. 2013.123

Villa, I., Vedda, A., Cantarelli, I. X., Pedroni, M., Piccinelli, F., Bettinelli, M., et al. (2015). $1.3 \mu \mathrm{m}$ emitting $\mathrm{SrF}_{2}: \mathrm{Nd}^{3+}$ nanoparticles for high contrast in vivo imaging in the second biological window. Nano Res. 8, 649-665. doi: 10.1007/s12274-014-0549-1

Wang, D., Rogach, A.L., and Caruso, F. (2002). Nanocrystal-labeled biofunctional colloids. Nano Lett. 2:857. doi: 10.1021/nl025624c 
Wang, D., Wang, D., Kuzmin, A., Pliss, A., Shao, W., Xia, J., et al. (2018). ICG-sensitized $\mathrm{NaYF}_{4}$ : er nanostructure for theranostics. Adv. Opt. Mater. 6:1701142. doi: 10.1002/adom.201701142

Wang, F., and Liu, X. (2009). Recent advances in the chemistry of lanthanide-doped upconversion nanocrystals. Chem. Soc. Rev. 38, 976-989. doi: 10.1039/b809132n

Wang, F., Zhang, Y., Fan, X., and Wang, M. (2006). Facile synthesis of water-soluble $\mathrm{LaF}_{3}$ : Ln 3+ nanocrystals. J. Mater. Chem.16, 1031-1034. doi: $10.1039 / \mathrm{b} 518262 \mathrm{j}$

Wang, H., Agarwal, P., Zhao, S., Yu, J., Lu, X., and He, X. (2015). A biomimetic hybrid nanoplatform for encapsulation and precisely controlled delivery of theranostic agents. Nat. Commun. 6, 1-13.doi: 10.1038/ncomms10081

Wang, P., Fan, Y., Lu, L., Liu, L., Fan, L., Zhao, M., et al. (2018). NIR-II nanoprobes in-vivo assembly to improve image-guided surgery for metastatic ovarian cancer. Nat. Commun. 9:2898. doi: 10.1038/s41467-018-05113-8

Wang, Q., Tan, M. C., Zhuo, R., Kumar, G. A., and Riman, R. E. (2010). A solvothermal route to size-and phase-controlled highly luminescent $\mathrm{NaYF}_{4}$ : Yb, Er up-conversion nanocrystals. J. Nanosci. Nanotechnol. 10, 1685-1692. doi: 10.1166/jnn.2010.2120

Wang, R., Li, X., Zhou, L., and Zhang, F. (2014). Epitaxial seeded growth of rare-earth nanocrystals with efficient $800 \mathrm{~nm}$ near-infrared to $1525 \mathrm{~nm}$ short-wavelength infrared downconversion photoluminescence for in vivo bioimaging. Angew. Chem. Int. Ed. 53, 12086-12090. doi: 10.1002/anie.201407420

Wang, S., Fan, Y., Li, D., Sun, C., Lei, Z., Lu, L., et al. (2019a). Anti-quenching NIRII molecular fluorophores for in vivo high-contrast imaging and $\mathrm{pH}$ sensing. Nat. Commun.10, 1-11. doi: 10.1038/s41467-019-09043-x

Wang, S., Liu, L., Fan, Y., El-Toni, A. M., Alhoshan, M. S., Li, D., et al. (2019b). In vivo high-resolution ratiometric fluorescence imaging of inflammation using NIR-II nanoprobes with $1550 \mathrm{~nm}$ emission. Nano Lett. 19, 2418-2427.doi: 10.1021/acs.nanolett.8b05148

Wang, X., Li, H., Li, F., Han, X., and Chen, G. (2019c). Prussian bluecoated lanthanide-doped core/shell/shell nanocrystals for NIR-II image-guided photothermal therapy. Nanoscale 11, 22079-22088. doi: 10.1039/C9NR07973D

Wang, Y. F., Liu, G. Y., Sun, L. D., Xiao, J. W., Zhou, J. C., and Yan, C. H. (2013). $\mathrm{Nd}^{3+}$-sensitized upconversion nanophosphors: efficient in vivo bioimaging probes with minimized heating effect. ACS Nano. 7, 7200-7206. doi: $10.1021 / \mathrm{nn} 402601 \mathrm{~d}$

Weissleder, R., and Pittet, M. J. (2008). Imaging in the era of molecular oncology. Nature 452, 580-589. doi: 10.1038/nature06917

Weissleder, R., Schwaiger, M. C., Gambhir, S. S., and Hricak, H. (2016). Imaging approaches to optimize molecular therapies. Sci. Transl. Med. 8:355ps16. doi: 10.1126/scitranslmed.aaf3936

Willmann, J. K., Van Bruggen, N., Dinkelborg, L. M., and Gambhir, S. S. (2008). Molecular imaging in drug development. Nat. Rev. Drug Discov. 7, 591-607. doi: $10.1038 / \mathrm{nrd} 2290$

Winer, J. H., Choi, H. S., Gibbs-Strauss, S. L., Ashitate, Y., Colson, Y. L., and Frangioni, J. V. (2010). Intraoperative localization of insulinoma and normal pancreas using invisible near-infrared fluorescent light. Ann. Surg. Oncol. 17, 1094-1100. doi: 10.1245/s10434-009-0868-8

Xue, Z., Zeng, S., and Hao, J. (2018). Non-invasive through-skull brain vascular imaging and small tumor diagnosis based on NIR-II emissive lanthanide nanoprobes beyond $1500 \mathrm{~nm}$. Biomaterials 171, 153-163. doi: 10.1016/j.biomaterials.2018.04.037

Yang, Q., Li, X., Xue, Z., Li, Y., Jiang, M., and Zeng, S. (2018). Short-wave nearinfrared emissive $\mathrm{GdPO}_{4}$ : $\mathrm{Nd}{ }^{3+}$ theranostic probe for in vivo bioimaging beyond $1300 \mathrm{~nm}$. RSC Adv. 8, 12832-12840. doi: 10.1039/C7RA12864A

Yang, Y., Aw, J., and Xing, B. (2017c).Nanostructures for NIR lightcontrolled therapies. Nanoscale 9, 3698-3718. doi: 10.1039/C6NR0 $9177 \mathrm{~F}$
Yang, Y., Chao, Y., Liu, J., Dong, Z., He, W., Zhang, R., et al. et al. (2017a). Coreshell and co-doped nanoscale metal-organic particles (NMOPs) post-synthesis cation exchange for multimodal imaging and synergistic thermo-radiotherapy. NPG Asia Mater. 9:e344. doi: 10.1038/am.2016.205

Yang, Y., Mu, J., and Xing, B. (2017b).Photoactivated drug delivery and bioimaging. Wiley Interdiscip. Rev. Nanomed. Nanobiotechnol. 9:e1408. doi: 10.1002/wnan.1408

Yu, Z. F., Shi, J. P., Li, J. L., Li, P. H., and Zhang, H. W. (2018). Luminescence enhancement of $\mathrm{CaF}_{2}: \mathrm{Nd}^{3+}$ nanoparticles in the second near-infrared window for in vivo imaging through $\mathrm{Y}^{3+}$ doping. J. Mater. Chem. B 6, 1238-1243. doi: 10.1039/C7TB03052E

Yuan, D., Tan, M. C., Riman, R. E., and Chow, G. M. (2013). Comprehensive study on the size effects of the optical properties of $\mathrm{NaYF}_{4}$ : Yb, Er nanocrystals. $J$. Phys. Chem. C 117, 13297-13304. doi: 10.1021/jp403061h

Zevon, M., Ganapathy, V., Kantamneni, H., Mingozzi, M., Kim, P., Adler, D., et al. (2015). CXCR-4 targeted, short wave infrared (SWIR) emitting nanoprobes for enhanced deep tissue imaging and micrometastatic cancer lesion detection. Small 11, 6347-6357. doi: 10.1002/smll.201502202

Zhang, F., Wan, Y., Yu, T., Zhang, F., Shi, Y., Xie, S., et al. (2007). Uniform nanostructured arrays of sodium rare-earth fluorides for highly efficient multicolor upconversion luminescence. Angew. Chem., Int. Ed. 46, 7976-7979. doi: 10.1002/anie.200702519

Zhang, H., Chen, Z. H., Liu, X., and Zhang, F. (2020). A mini-review on recent progress of new sensitizers for luminescence of lanthanide doped nanomaterials. Nano Res. 1-15. doi: 10.1007/s12274-020-2661-8

Zhang, H., Fan, Y., Pei, P., Sun, C., Lu, L., and Zhang, F. (2019). Tm ${ }^{3+}$-Sensitized NIR-II Fluorescent Nanocrystals for in vivo Information Storage and Decoding. Angew. Chem.131, 10259-10263. doi: 10.1002/ange.201903536

Zhang, X., Zhao, Z., Zhang, X., Cordes, D. B., Weeks, B., Qiu, B., et al. (2015). Magnetic and optical properties of $\mathrm{NaGdF}_{4}: \mathrm{Nd}^{3+}, \mathrm{Yb}^{3+}$, $\mathrm{Tm}^{3+}$ nanocrystals with upconversion/downconversion luminescence from visible to the near-infrared second window. Nano Res. 8, 636-648. doi: 10.1007/s12274-014-0548-2

Zhao, M., Li, B., Wang, P., Lu, L., Zhang, Z., Liu, L., et al. (2018). Supramolecularly engineered NIR-II and upconversion nanoparticles in vivo assembly and disassembly to improve bioimaging. Adv. Mater. 30:1804982. doi: 10.1002/adma.201804982

Zhao, M., Wang, R., Li, B., Fan, Y., Wu, Y., Zhu, X., et al. (2019). Precise in vivo inflammation imaging using in situ responsive cross-linking of glutathionemodified ultra-small NIR-II lanthanide nanoparticles. Angew. Chem. 131, 2072-2076. doi: 10.1002/ange.201812878

Zhao, Z., Kantamneni, H., He, S., Pelka, S., Venkataraman, A. S., Kwon, M., et al. (2018). Surface-modified shortwave-infrared-emitting nanophotonic reporters for gene-therapy applications. ACS Biomater. Sci. Eng. 4, 2350-2363. doi: 10.1021/acsbiomaterials.8b00378

Zhong, Y., Ma, Z., Zhu, S., Yue, J., Zhang, M., Antaris, A. L., et al. (2017). Boosting the down-shifting luminescence of rare-earth nanocrystals for biological imaging beyond $1500 \mathrm{~nm}$. Nat. Commun. 8:737. doi: 10.1038/s41467-017-00917-6</A >

Conflict of Interest: The authors declare that the research was conducted in the absence of any commercial or financial relationships that could be construed as a potential conflict of interest.

Copyright (c) $2020 \mathrm{Yu}$, Eich and Cruz. This is an open-access article distributed under the terms of the Creative Commons Attribution License (CC BY). The use, distribution or reproduction in other forums is permitted, provided the original author(s) and the copyright owner(s) are credited and that the original publication in this journal is cited, in accordance with accepted academic practice. No use, distribution or reproduction is permitted which does not comply with these terms. 